Article

\title{
Acoustic Properties of Musanga Cecrepoides Wood Samples Obtained from Different Stem Positions in Niger Delta Region of Nigeria
}

\author{
Aleru K. K., Owoyemi J.M., Olufemi B., Adeniran A. T. \\ Department of Forestry and Wood Technology, Federal University of Technology Akure, Akure, Ondo State, \\ Nigeria \\ *Correspondence: adeniranta@futa.edu.ng
}

How to cite this paper: Aleru, K. K., Owoyemi, J. M., Olufemi, B., \& Adeniran, A. T. (2021). Acoustic Properties of Musanga Cecrepoides Wood Samples Obtained from Different Stem Positions in Niger Delta Region of Nigeria. Open Journal of Agricultural Research, 1(1), 17-24. DOI: 10.31586/ojar.2021.010104. Retrieved from https://www.scipublications.com/journal/in-

dex.php/ojar/article/view/81

\begin{abstract}
Musanga cecrepoides is an interesting wood species due to its diverse utility ranging from medicine, shade, ornaments etc. Research has been conducted on other properties of this wood species with little information about its acoustic properties. Thus, the evaluation of its acoustic properties is pertinent so as to increase the information bank of its properties. This study assessed the acoustic properties of Musanga cecrepoides wood obtained from selected states and locations in the Niger Delta region of Nigerian viz a vis, Rivers, Bayelsa and Delta States. Test samples were collected from different stem positions axially (top, middle, base) and radially (inner and outer) and analyzed using the statistical software package IBM SPSS Statistics, Version 23 (IBM Corporation, New York, USA). Analysis of variance (ANOVA) was performed at $5 \%$ level of significance to determine whether the assessed acoustic properties were significantly different among different stem positions. Results showed that sound frequency (f) at top wood $(3061.71 \mathrm{~Hz})$ and outer wood (3096.06 Hz) had significantly higher resonance frequency compared with the bottom wood $(2768.01 \mathrm{~Hz})$ and inner wood $(2349.54 \mathrm{~Hz})$ respectively. The mean sound velocity $(\mathrm{v})$ at both the axial $(2069.59 \mathrm{~m} / \mathrm{s})$ and radial $(1905.96 \mathrm{~m} / \mathrm{s})$ stem positions fell short of the estimated mean $\mathrm{v}$ of other wood species when compared. However, such result is suitable for other acoustic purposes with moderate sound velocity. The sound radiation coefficient $(\mathrm{R})$ values were highest at the bottom (4.18) axially and outer (4.13) radially when compared to other stem orientations of the wood. Whereas axially at the top $\left(1561815.86 \mathrm{Kg} /\left(\mathrm{m}^{2} \mathrm{~s}\right)\right)$ and radially at the outer position $\left(1558292.53 \mathrm{Kg} /\left(\mathrm{m}^{2} \mathrm{~s}\right)\right.$ Sound Impedance $(\mathrm{z})$ was highest when compared with other stem positions of the Musanga cecrepoides wood.
\end{abstract}

Keywords: Musanga cecrepoides, Sound, frequency, velocity, radiation coefficient, impedance

\section{Introduction}

In spite of recent advances in material science, wood remains a preferred material for acoustic applications due to its inherent properties. The distinguishing features of wood when compared with other materials includes light weight, workability and sound energy efficiency [1]. Apart from its ability to produce sound when strike, wood can also amplify and absorb sound waves originating from other bodies. When sound waves of extrinsic origin strike wood, they are partly absorbed and partly reflected, and the wood is set in vibration. For these reasons, wood is a favoured material for musical instruments and other acoustic applications.

Wood has been utilized in the production of many musical instruments such as guitar, violin, piano, xylophone and percussion [2]. However, poor selection of wood species has hindered optimal performance of wood for acoustic purposes [3]. When wood is used 
for acoustic purposes, the pitch and quality of sound produced, the rate of sound absorption and reflection depends on the frequency of vibration [4] and varies between and within wood species.

The opportunity to explore the acoustic properties of various wood species for manufacturing high quality musical instruments abounds in Nigeria. However, scientific information on the suitability of wood species for musical instruments is still lacking and manufacturers in Nigeria relied on few wood species whose suitability have been proven through trial and error and indigenous knowledge for making musical instruments. Therefore, the wood species that have been selected and being used by experienced manufacturers in making musical instruments are very limited, such as Cordia millenni [5], thereby putting pressure on these few selected species. Overtime, multiple use of these species for musical instruments and other wood-based industries resulted in shortage of supply and forced the industry to utilize many unsuitable species for acoustic purposes which eventually render unsatisfactory services to end users.

In order to put an end to overdependence on few species for acoustic purposes in Nigeria, and recommend other wood species for optimal acoustic performance, there is need to provide scientific information on the suitability of various wood species for acoustic purposes. The suitability of wood for musical instruments and other acoustic purposes can be scientifically determined through the evaluation of certain parameters such as sound frequency, sound velocity, speed of sound, impedance, and sound radiation coefficient.

This study is therefore designed to determine acoustic properties of Musanga cecropoides from mangrove forests in Niger Delta, Nigeria and determine their suitability for making acoustic instruments like drums, violin and guitar.

\section{Materials and Methods}

\section{Study Area}

The test samples were obtained from three selected states/location (Figure1) in the Niger-Delta region of Nigeria viz Obugwo Forest, Egbeda, Emouha Local Government Area of Rivers State, Nigeria as which lies between Latitude $5014^{\prime} 5^{\prime} \mathrm{N}$ and Longitude $6045^{\prime} 9$ E, Subai Igbangi Forest in Kolokuma/Opokuma Local Government area of

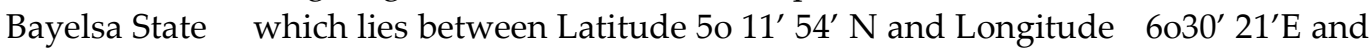
Patani Forest, Patani Local Government Area of Delta State and lies between Latitude 5o $13^{\prime} 43^{\prime \prime} \mathrm{N}$ and Longitude 6o11' $33 \mathrm{E}$. The locations are mainly agrarian in nature with standing trees of Musanga cecropoides which were selected and felled for this study.

The people of the Niger Delta's economic lives are greatly influenced by their environment. Fishermen and traders abound along the coastal areas, while those in the hinterland grow food crops like cassava, yam, and vegetables, as well as cash crops like oil palm and rubber.

\section{Sample Preparation}

Wood samples of Musanga cecropoides (Umbrella tree) were prepared as a rectangular test specimen with dimensions $350 \mathrm{~mm} \times 45 \mathrm{~mm} \times 20 \mathrm{~mm}$. Wood samples were collected axially from the bottom, middle, top and radially from inner and outer stem positions. The rectangular wood bars were subjected to acoustic properties test in a serene enclosure devoid of any sound, wave or disturbance to determine the sound frequency, wavelength and time taken to produce sound effects from the wood bars.

\section{Experimental Setup}

The experimental set-up for the acoustic test is as shown in Figure 2. A microphone was placed on a stand and connected to a sound mixer and oscilloscope. The wood bars 
were paced on a rubber band to ensure a free free-type boundary conditions and to minimize pertubations due to suspension.

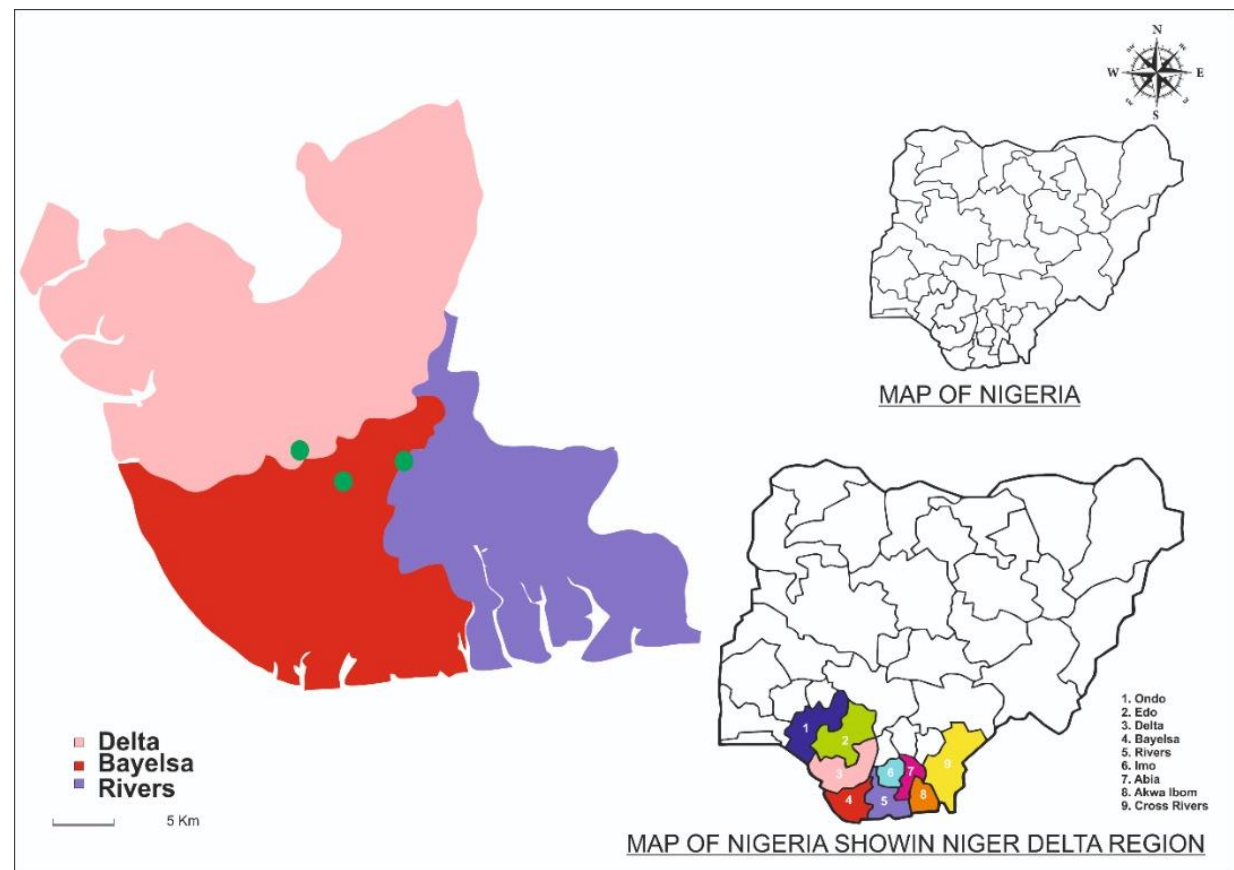

Figure 1. Map Showing Niger Delta States from which the study was conducted

The suspended wood bars were positioned at a short distance of $0.1 \mathrm{~m}$ from the microphone and striked severally with a pendulum ball of $14 \mathrm{~mm}$ diameter and weight of $12 \mathrm{~g}$ at low mild and high pitches to trigger a vibration in the wood specimen by hitting the end.

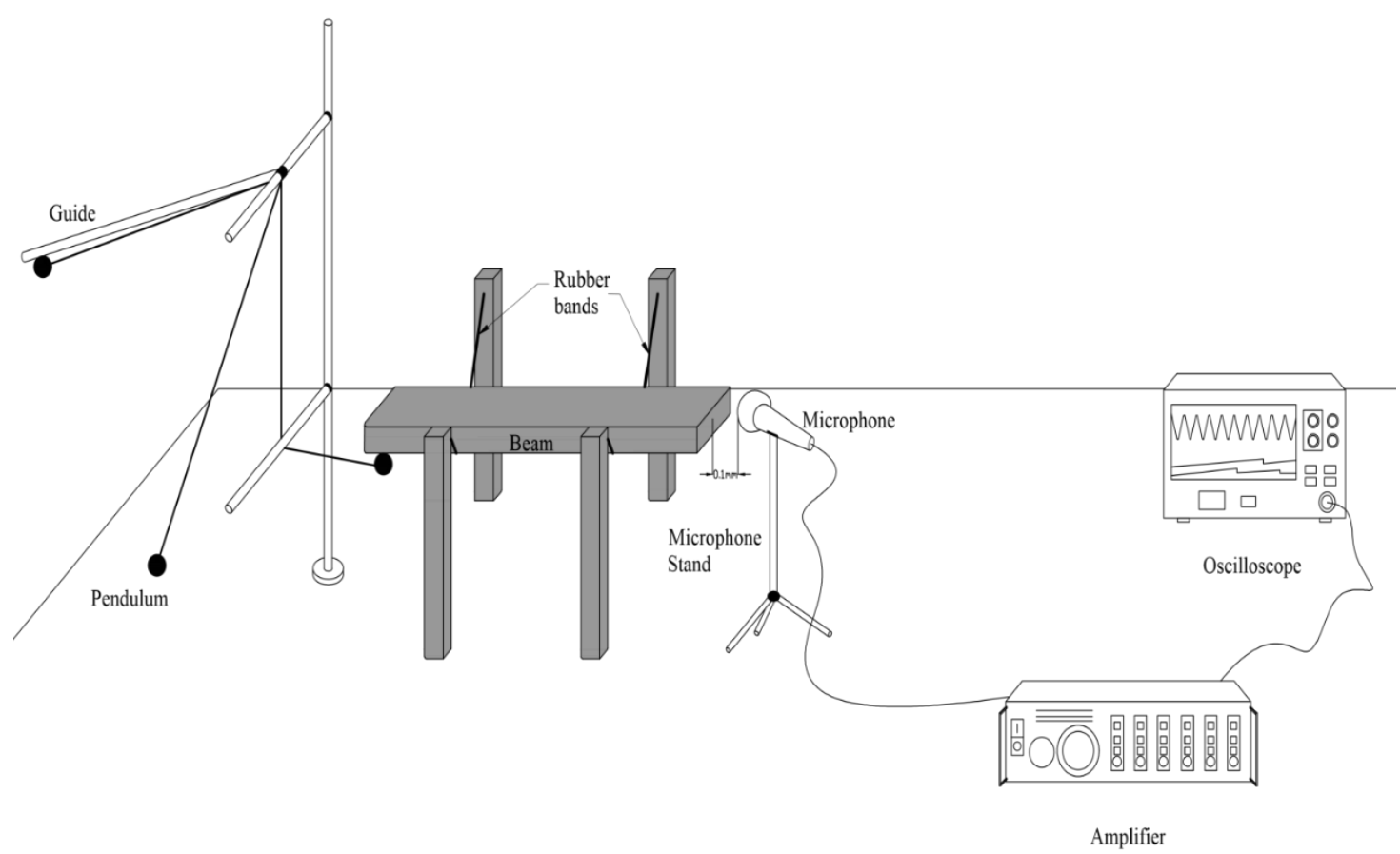

Figure 2. Schematic representation of experimental set-up for Acoustic Properties. 
The sound frequency effects produced was recorded with the aid of an oscilloscope while appropriate formulas were used to calculate derived parameters such as sound velocity, impedance, speed of sound and sound radiation coefficient as adopted by Noah et al. [6] Formulas used for calculation of Derived Parameters

$$
\begin{aligned}
& \mathrm{f}=\mathrm{v} / \lambda \quad(\mathrm{Hz}) \\
& \mathrm{V}=\mathrm{f} \times \lambda(\mathrm{m} / \mathrm{s}) \\
& \mathrm{V}=2 \mathrm{Lf} \\
& \mathrm{C}=\sqrt{\mathrm{E}} / \mathrm{P}(\mathrm{m} / \mathrm{s}) \\
& \mathrm{z}=\mathrm{c} \times \mathrm{p} \\
& \mathrm{R}=\mathrm{C} / \mathrm{P}=\sqrt{\mathrm{E}} / \mathrm{P}^{\wedge} 3
\end{aligned}
$$

Where:

$\mathrm{f}=$ Frequency

$\mathrm{V}=$ velocity of sound

$\lambda=$ wavelength $=2 \mathrm{~L} / \mathrm{n}$; and $\mathrm{L}=$ length of the sample; $\mathrm{n}=$ number of resonance mode

$\mathrm{C}=$ speed of sound

$\mathrm{E}=$ Modulus of Elasticity

$\mathrm{P}=$ Density

$\mathrm{Z}=$ Impedance

\section{Data analysis}

Data obtained were analyzed using the statistical software package IBM SPSS Statistics, Version 23 (IBM Corporation, New York, USA). Analysis of variance (ANOVA) was performed to at $5 \%$ level of significance to determine whether the assessed acoustic properties were significantly different among different stem positions. When significant differences were found, Duncan's multiple-range test was performed.

\section{Results and Discussions}

\section{Sound Frequency}

Sound frequency of a material is measured by the number of whole cycle of a vibration per second produced as a result of particle disturbance in the travel medium [7]. Therefore, since sound frequency at top wood and outer wood of Musanga cecrepoides wood had a higher resonance frequency compared with the bottom wood and inner wood respectively, higher sound pitch is expected when the top outer wood is used as material for acoustic instruments (Figure 3). On the other hand, sound frequency at bottom wood and outer wood was higher axially and radially. Thus, this implies that provided resonance frequency remain constant, bottom wood and outer wood would have the highest pitch of sound. Meaning, bottom wood as well as outer wood would be expected to best support any musical instrument requiring a high pitch of sound with which it was used to manufacture. This result is in agreement with Olaoye et al. [3].

However, Analysis of Variance (ANOVA) done for sound frequency indicated that results obtained from the different axial and radial were not significantly different. For this reason, sound frequency obtained in this study at the different stem positions are the same, and as such none has performed better than the other. 


\section{SOUND FREQUENCY}

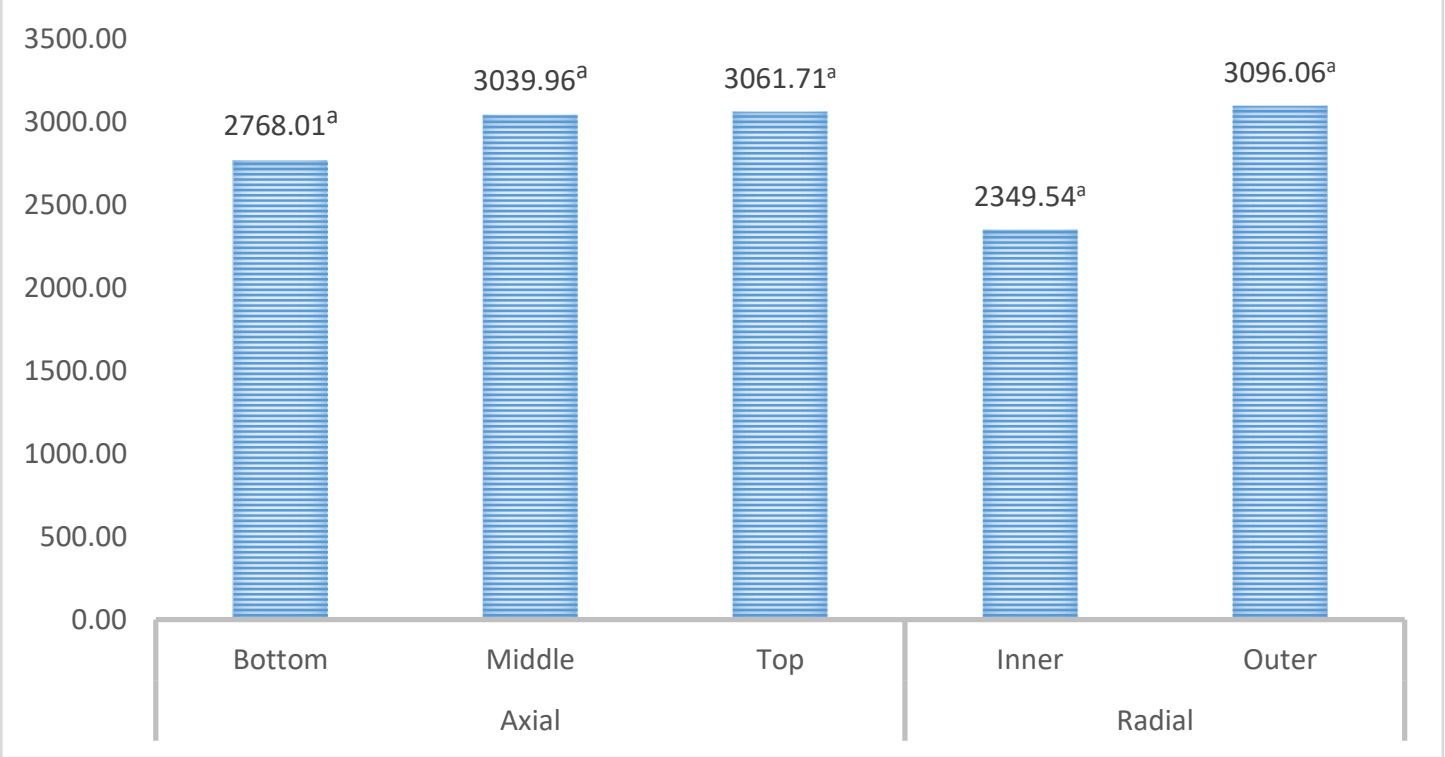

Figure 3. Sound frequency of Musanga cecrepoides wood samples obtained from Axial and Radial stem positions

Means with the same letter are not significantly different (Duncan's Multiple Test at $P \leq 0.05$ )*

\section{Speed of sound (c) and Sound Velocity (v)}

The velocity of sound which is defined as the distanced travelled per unit time by a sound wave as it propagates through elastic medium. The velocity of sound in wood means that the speed at which wood transmits received energy. Wood with a high sound velocity and low internal damping, best facilitate the transmission of vibrational energy [8]. Therefore, sound velocity is an essential parameter to consider before recommending a material acoustically suitable, especially for making musical instrument. Thus, a higher value of velocity of sound is essential for making a better choice. Results in Figure 3 and 4 shows that top wood and outer wood had higher values along and across the bole respectively, however analysis of variance shows no significant differences. Therefore, these values are assumed the same.

Meanwhile, the mean velocity for Musanga cecrepoides obtained in this study is within lower than the estimated range of velocity of sound for wood $(3300 \mathrm{~m} / \mathrm{s}-6500 \mathrm{~m} / \mathrm{s})$ [9]. Additionally, higher values were reported for G. arborea (of $3068.66 \mathrm{~m} / \mathrm{s}$ ) [6], Brachystegia eurycoma (3712.35 m/s) [6], A. robusta and ( $3711.46 \mathrm{~m} / \mathrm{s})$ [10]. Inferentially, Musanga cecrepoides can be considered as one of the suitable wood species for acoustic purposes only where moderate sound velocity is required. However, this sound speed factor alone does not determine the quality wood for musical instruments and other acoustic properties play also a role. 


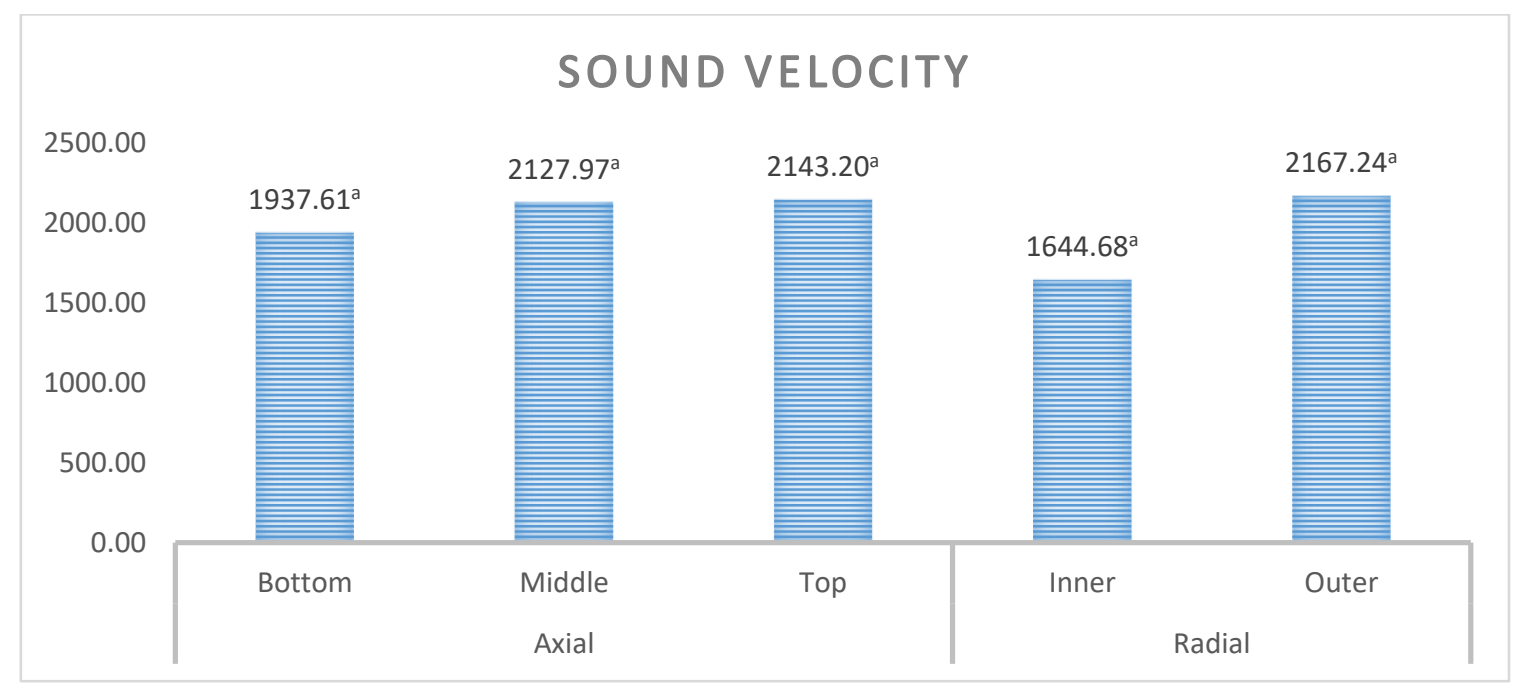

Figure 4. Sound Velocity of Musanga cecrepoides wood samples obtained from Axial and Radial stem positions

Means with the same letter are not significantly different (Duncan's Multiple Test at $P \leq 0.05)^{*}$

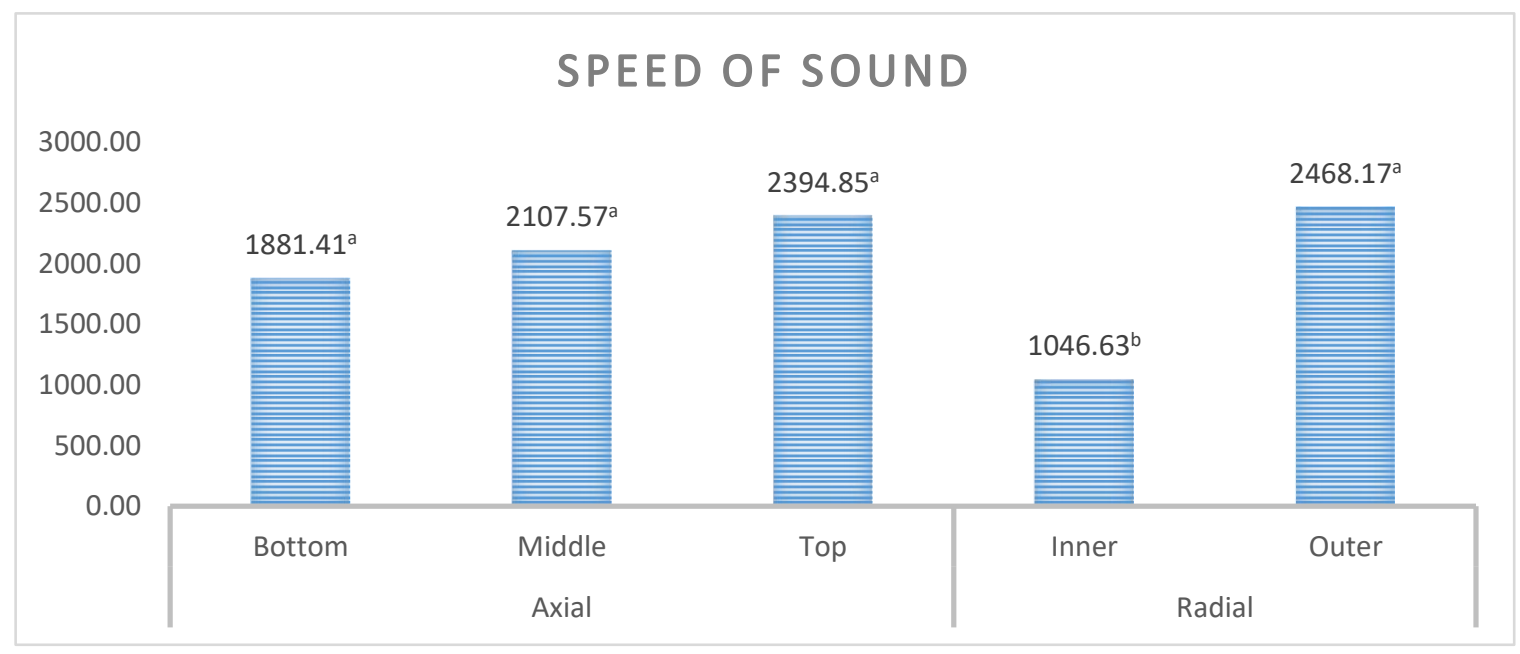

Figure 5. Speed of sound of Musanga cecrepoides wood samples obtained from Axial and Radial stem positions

Means with the same letter are not significantly different (Duncan's Multiple Test at $P \leq 0.05)^{*}$

\section{Sound radiation coefficient $(\mathrm{R})$}

Sound radiation coefficient $(\mathrm{R})$ is a measure of the vibration within the wood as it is damped by radiating sound. A high $R$ of the material is desirable to produce a loud sound and in this sense, it is essential for its resonance quality.

Figure 6 shows that Musanga cecrepoides wood obtained from bottom and outer portion had higher $\mathrm{R}$ values than those obtained from middle, top and inner stem position and that significant difference exist in the $\mathrm{R}$ of wood obtained from different radial position of Musanga cecrepoides This makes them the bottom outer wood portion of Musanga cecrepoides more suitable for soundboard making. Wood for sound instruments like xylophone bars, violin bows and wind instruments require $\mathrm{R}$ values between 4 and $8 \mathrm{~m} 4 \mathrm{~kg}-1$ s-1 [9]. This makes the bottom outer wood portion of Musanga cecrepoides ideal for these applications. 


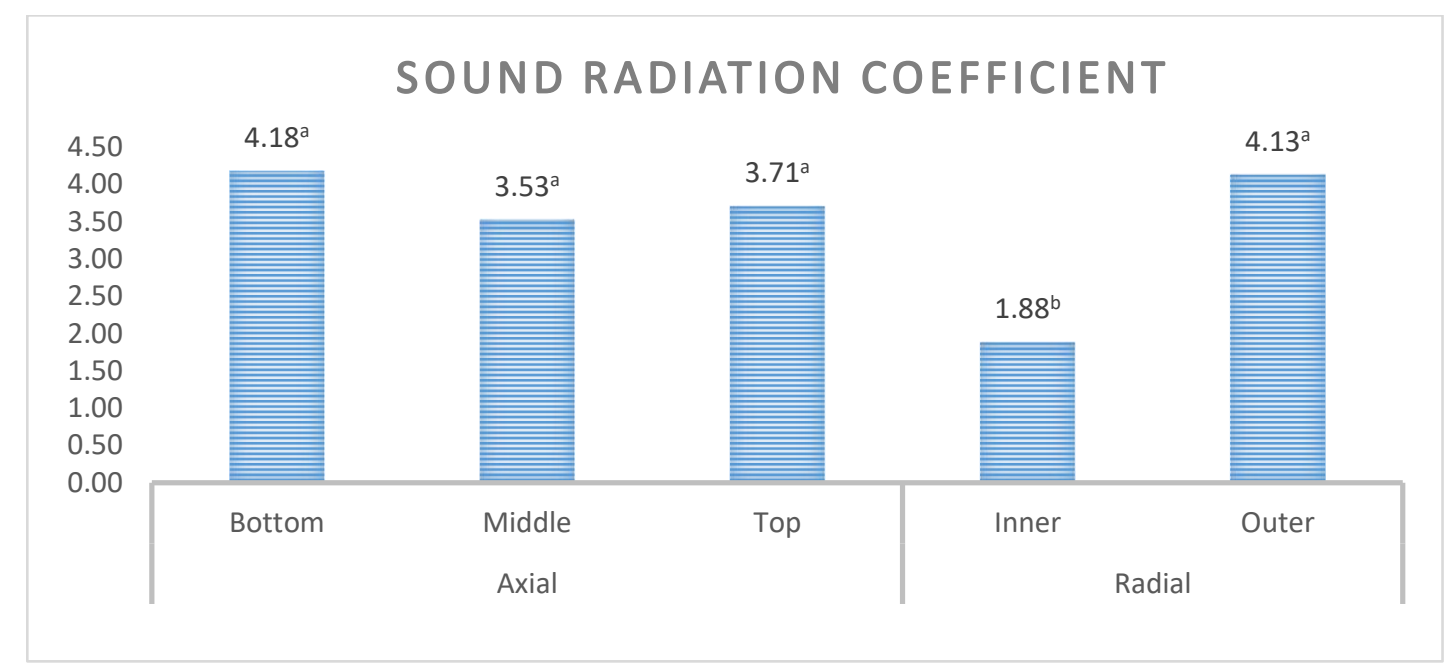

Figure 6. Sound Radiation Coefficient of Musanga cecrepoides wood samples obtained from Axial and Radial stem positions

Means with the same letter are not significantly different (Duncan's Multiple Test at $P \leq 0.05$ )*

\section{Specific Acoustic impedance (z)}

Acoustic impedance of a medium is the rate of resistance of a medium to sound flow travelling through it (Olaoye et al., 2016). Thus, a high value of impedance should imply a high rate of reflection of sound wave by the medium with which it travels in. Like $C$ and $\mathrm{R}$, the specific acoustic impedance, $\mathrm{z}$, of a material is directly related to its elastic modulus and density. This parameter is important when vibrational energy is transmitted from one medium to another. The first medium could be a string and the second the main body of a musical instrument. It is an important value particularly for string instruments and often it is required a low $\mathrm{z}[9,11]$. A low $\mathrm{z}$ is beneficial for sound transmission into the air. A low $\mathrm{z}$ value is required for string instruments and high value $\mathrm{z}$ is required for percussion instruments such as xylophones so that resonance will be for a longer period of time [11]. In that aspect, all wood materials of Musanga cecrepoides obtained in this study were found to have appropriate $\mathrm{z}$ values required for percussion instruments based on their impedance values (Figure 7).

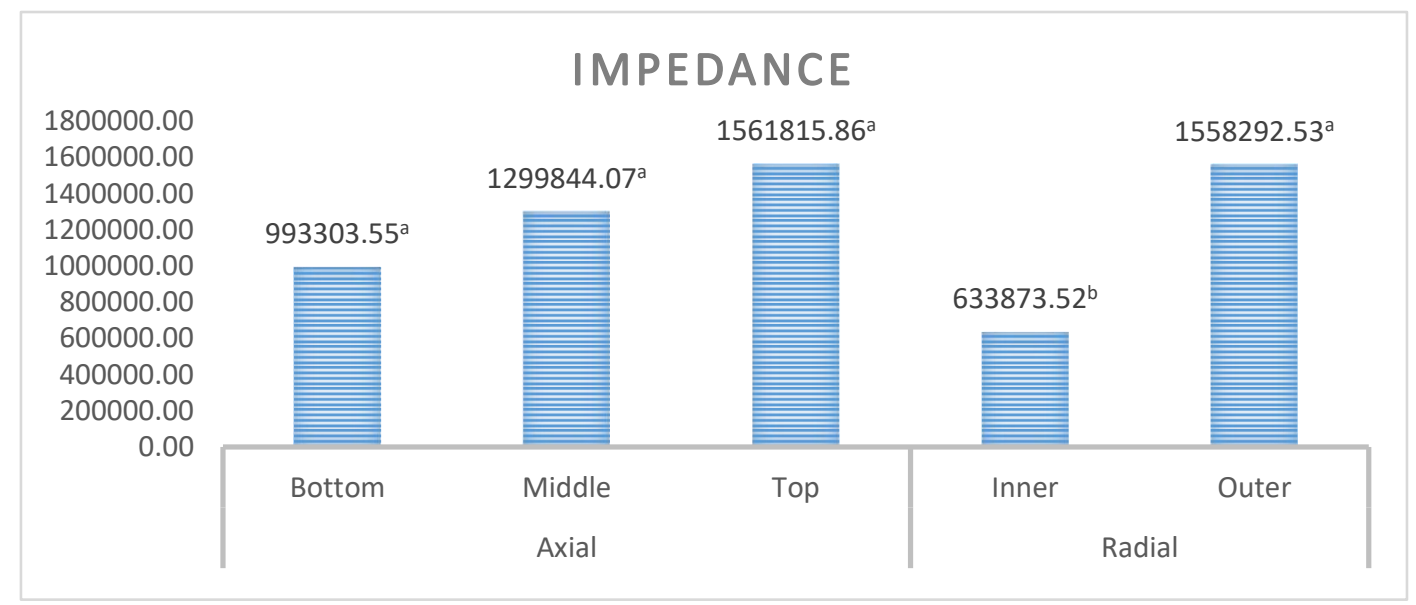

Figure 7. Impedance of Musanga cecrepoides wood samples obtained from Axial and Radial stem positions

Means with the same letter are not significantly different (Duncan's Multiple Test at $P \leq 0.05$ )* 


\section{Conclusions}

- This study investigated the acoustic properties of Musanga cecrepoides wood, and thus concluded that Musanga cecrepoides wood is a good choice for certain acoustic purposes. Although, it has lesser desired values of acoustic properties when compared favorably with some other wood species.

- $\quad$ The top wood portion of Musanga cecrepoides was found to have superior sound frequency, sound velocity, speed of sound and impedance while the bottom wood portion had higher value of sound radiation coefficient.

- The outer wood portion performed better than the inner wood in all assessed acoustic properties.

- As such precaution should be taken when selection of wood species on the basis of its acoustic properties as the top and outer portion of the wood was observed to have superior acoustic properties to the top inner portion.

- $\quad$ The acoustic traits of the top outer wood may be suitable making certain musical shell; such as sound boxes and sound boards for musical instruments, while the properties of the top inner portion may be needed when considering the same wood species for frame board or construction of musical studio.

\section{References}

[1] Yoshikawa S. and Waltham C. (2014). Wood for wooden instrument; why wood? ISMA, Le Mans, France. $2014: 282$

[2] Olaoye K. O. and Okanlawon F. B. (2019) Acoustic Properties of Albizia Adianthifolia (schum.) Wood in Relation to Moisture. American Journal of Agriculture and Forestry. Vol. 7, No. 3, 2019, pp. 119-125. doi: 10.11648/j.ajaf.20190703.15

[3] Olaoye, K. O., Oluwadare A. O., Adelusi E. A. and Abiola J. K. (2019). Acoustic Properties of Gmelina arborea (Roxb.) Wood. Journal of Materials Science Research and Reviews, 4(1): 1-9.

[4] Tsoumis G. (1991). Science and technology of wood-structure, properties utilization. New York: Van Nostrand Reinhold; 1991

[5] Aiyeloja, A. A., Adedeji, G. A. and Adebisi L. A. (2015). Suitability of Gmelina arborea (Roxb.) wood for making talking drum in Nigeria. IOSR Journal of Agriculture and Veterinary Science. Volume 8, Issue 2, PP 95-100

[6] Noah A. S., Abiola J. K., Ayeni O. D., Bamidele O. D. and Alao O. J. (2014) Comparative assessment of selected acoustic properties of talking drums made from wood of Gmelina arborea (Roxb) and Brachystegia eurycoma (Harms). Journal of Multidisciplinary Engineering Science and Technology (JMEST). 2014;1(5):22-27.

[7] Plack C. J., Andrew J. and Oxenham, R. (2005). Pitch: Neural Coding and Perception. New York: Springer; 2005. ISBN 0-38723472-1

[8] Ahmed, S. A., \& Adamopoulos, S. (2018). Acoustic properties of modified wood under different humid conditions and their relevance for musical instruments. Applied Acoustics, 140, 92-99. doi: 10.1016/j.apacoust.2018.05.017

[9] Wegst U. G.K. (2006) Wood for sound. Am J Bot 2006;93(10):1439-48. http://dx.doi.org/0.3732/ajb.93.10.1439.

[10] Olaoye K. O., Oluwadare A. O., Kolapo M. A. and Akala A. O. (2016). Acoustic potential of Aningeria robusta (A. chev) wood for manufacturing talking drum. Proceeding of the 5th biennial conference of the forest and forest products society, Nigeria. 2016;466-470.

[11] Hilde C., Woodward R., Avramidis S., Hartley I. D. (2014). The acoustic properties of water submerged lodgepole Pine (Pinus contorta) and spruce (Picea spp.) wood and their suitability for use as musical instruments. Materials 2014;7(8):5688-99. http://dx. doi.org/10.3390/ma7085688. 